\title{
VOLUME LIMITATION REDUCES EARLY SIGNIFICANT HYPOCARBIA IN PRETERM VENTILATED INFANTS IN A BUSY TERTIARY NEONATAL SETTING
}

\author{
J. Berrington, D. Summers, H. Van Ruiten
}

Newcastle Neonatal Service, Newcastle upon Tyne Hospitals NHS Trust, Newcastle upon Tyne, UK

Background and aims: Hypocarbia in preterm infants affects neurodevelopmental outcome. We showed by repeated audit that preterm ventilated infants were routinely running low $\mathrm{CO}_{2}(<4.5)(25 \%$ in 2008$)$, despite educational interventions. We therefore added volume limitation to our normal pressure controlled ventilation in 2010. We evaluated the impact by auditing blood gas values.

Methods: Audit of blood gas $\mathrm{CO}_{2}$ levels of preterm ventilated infants managed with volume limitation in comparison to previous audit data from before this change.

Results: 19 infants contributed 109 gases during their first 24 hours of life. $6 \%$ of these had a $\mathrm{pCO}_{2}<4.5$ in comparison to $25 \%$ from the previous cohort. There was no increase in very high levels of $\mathrm{pCO}_{2}$ (defined as $>7.5)$.

\begin{tabular}{|l|l|l|}
\hline CO2 value $(\mathrm{mmHg})$ & No Volume limitation $(2008)$ & Volume limitation \\
\hline$<4.5$ (very low) & 25 & 6 \\
\hline $4.5-5.9$ (low) & 50 & 38 \\
\hline $6-7.5$ (target) & 18 & 48 \\
\hline$>7.5$ & 7 & 8 \\
\hline
\end{tabular}

[Proprtion of gases with target CO2 values]

Conclusions: Volume limitation successfully reduced the number of blood gases with very low levels of $\mathrm{pCO}_{2}$ where education had failed. This was achieved without any increase in gases with a high $\mathrm{pCO}_{2}$. This method has been easily understood by a team experienced only in pressure limited ventilation. Other units that currently pressure ventilate may like to consider this method of helping to achieve targeted $\mathrm{CO} 2$ values without the need to switch to volume ventilation. 